\title{
Cognitive recovery after severe head injury
}

\section{Wechsler Adult Intelligence Scale during post-traumatic amnesia}

\author{
IAN A. MANDLEBERG
}

From the Department of Neurosurgery, Glasgow University, Glasgow

SYNOPSIS The Wechsler Adult Intelligence Scale (WAIS) was administered to two matched groups of severely head-injured patients. The first administration was early in the recovery period, when group I was still in post-traumatic amnesia. The WAIS results for this group were significantly lower than those of group II, who were fully conscious. A follow-up at a later stage of recovery found that group I had substantially caught up with group II on the WAIS. At both administrations the WAIS subtest scores were correlated with clinical data, and changes in the pattern of correlations between PTA and full consciousness suggested that the former represents a qualitatively, and not merely quantitatively, distinct phase of recovery.

Post-traumatic amnesia (PTA) is a period of clouded consciousness which precedes'the attainment of full orientation and continuous awareness in persons recovering from head injuries. Its duration, which may range from minutes to months, is claimed to be an index of the severity of the head injury (Russell, 1971). PTA appears to be characterized primarily by a failure of mnestic processes, insofar as the patient on subsequent questioning is able to recall at best only isolated incidents which occurred during this period. It is not surprising therefore to find that the psychological studies on head-injured persons during PTA have been concerned above all with memory (Fodor, 1972; Dunn and Brooks, 1974). With the possible exception of a paper by Ruesch and Moore (1943), studies of other cognitive abilities during this critical phase of recovery appear to be lacking, despite the fact that patients in PTA are often capable of speech and might therefore be supposed to be capable of submitting to psychological examination.

The present study seeks to contribute towards remedying this deficiency by reporting the results of the Wechsler Adult Intelligence Scale (WAIS), a widely used and well-standardized psychometric instrument (Wechsler, 1955), administered to patients during PTA. At the same (Accepted 17 June 1975.) time, it will complement the findings of an earlier study (Mandleberg and Brooks, 1975) which dealt with cognitive recovery over a period of approximately three years from the end of PTA. By examining the pattern of test results during and after PTA, together with their 'demographic' and clinical correlates, it may be possible to determine whether the return of continuous awareness signifies a qualitative or merely a quantitative change in the level of cognitive abilities. By following up the patients at a later stage of their recovery the validity of PTA duration as an index of severity of injury may be assessed with respect to the WAIS.

\section{METHOD}

SUBJECTS These were 32 adult head-injured patients admitted to the Division of Neurosurgery, Institute of Neurological Sciences, Glasgow University. They consisted of two groups, one of which was first tested while still in PTA, while the second group was out of PTA at the time of the first test. All were severe injuries, 30 with PTA $>$ one week, and the other two with four to seven days PTA.

Group I comprised 14 men and two women. They had a mean age of 29.31 years $(S D=13.76)$, with a mean of 10.31 years of education $(S D=1.44)$. The initial WAIS test was administered at a mean of 60 days (range $=14-120$ ) from date of injury. The mean PTA of this group was 110 days (range $=21$ days to approximately 10 months). 
Group II was selected from a pool of 119 other head-injured adults who had been tested to that point in time. For each member of group I a 'control' was chosen to match as closely as possible on the following variables: age, sex, education, and time from injury to initial administration of the WAIS. Thus, group II comprised 14 men and two women, with a mean age of 29.50 years $(S D=14.31)$ and a mean education of 10.25 years $(S D=1.56)$. The initial test was administered at a mean of 56 days from injury (range $=14-130$ ). No significant differences were found between the two groups on these three variables ( $t$ tests). However, all members of group II were unequivocally out of PTA at the time of the initial WAIS administration. Thus, the mean PTA of group II (19 days; range $=$ four-55 days) was significantly lower $(P<0.01)$ than that of group $I$.

The two groups having been selected, a comparison was made of the incidence of each of the following neurological signs: (1) skull fracture; (2) intracranial haematoma; (3) motor dysfunction (hemiparesis); (4) dysphasia; and (5) brain-stem signs. The results, together with the distributions of PTA, are presented in Table 1. The groups were well matched with respect to all signs except (3).

TABLE 1

INCIDENCE OF NEUROLOGICAL SIGNS AND PTA DURATIONS IN TWO MATCHED GROUPS OF HEAD-INJURED SUBJECTS

\begin{tabular}{lcc}
\hline & $\begin{array}{c}\text { Group I } \\
(N=16)\end{array}$ & $\begin{array}{c}\text { Group II } \\
(N=16)\end{array}$ \\
\hline Neurological signs & & \\
Skull fracture & 7 & 7 \\
Haematoma & 6 & 5 \\
Motor dysfunction & 14 & 10 \\
Dysphasia & 8 & 8 \\
Brain-stem signs & 5 & 3 \\
PTA duration (weeks) & & 2 \\
$<1$ & 0 & 10 \\
1-3 & 1 & 3 \\
$4-7$ & 5 & 1 \\
$8-11$ & 1 & 0 \\
$>12$ & 9 & \\
\hline
\end{tabular}

FOLLOW-UP PROCEDURE The subjects participating in this study were part of a series being investigated at the Institute of Neurological Sciences to determine the outcome of head injury on a variety of neurological, psychiatric, and psychological parameters. As such, all were recalled at intervals for assessment by the specialists concerned. Consequently, it was possible to match the follow-up times for both members of a group I/group II pair, however long after injury that proved to be. A wide range of follow-up times was chosen, varying between three months and four years, with a mean of 18 months for group I and 20 months for group II. A $t$ test revealed that the difference between the mean follow-up times was not significant.

The failure of some subjects to keep appointments, even after repeated requests, necessitated the elimination of both members of a group I/group II pair if only one of them failed to attend. Because of this, the follow-up results are based upon only 11 of the original 16 matched pairs.

\section{RESULTS}

WAIS RESUltS AT INITIAL TESTING Mean (scale) scores of the WAIS subtests, and mean IQs, are seen in Table 2. The Mann-Whitney $U$ test (Siegel, 1955) was employed to evaluate the significance of the differences between the two groups. While group I was still in PTA they were found to be significantly inferior to group II on all subtest and IQ scores, the differences being somewhat more marked for the Performance than for the Verbal subtests.

\section{TABLE 2}

WAIS MEAN (SCALE) SUBTEST AND IQ SCORES FOR TWO MATCHED GROUPS OF HEAD-INJURED SUBJECTS (INITIAL TESTING)

\begin{tabular}{lrrr}
\hline \multicolumn{1}{c}{ Subtest } & $\begin{array}{c}\text { Group I } \\
(N=16)\end{array}$ & $\begin{array}{l}\text { Group II } \\
(N=16)\end{array}$ & $U$ \\
\hline Verbal subtests & & & \\
$\quad$ Information & 5.69 & 8.75 & $61.0 \dagger$ \\
Comprehension & 4.75 & 9.50 & $36.5 \ddagger$ \\
Arithmetic & 4.69 & 9.69 & $35.0 \ddagger$ \\
Similarities & 5.44 & 8.46 & $53.0 \dagger$ \\
Digit span & 5.69 & 9.31 & $67.0 *$ \\
Vocabulary & 6.06 & 10.19 & $48.0 \dagger$ \\
Performance subtests & & & \\
Digit symbol & 0.68 & 4.63 & $23.5 \ddagger$ \\
Picture completion & 4.21 & 8.31 & $43.0 \ddagger$ \\
Block design & 2.56 & 6.88 & $38.5 \ddagger$ \\
Picture arrangement & 1.50 & 6.56 & $13.5 \ddagger$ \\
Object assembly & 1.19 & 6.06 & $16.0 \ddagger$ \\
IQs & & & \\
Verbal & 74.63 & 98.50 & $43.5 \ddagger$ \\
Performance & 50.56 & 80.13 & $8.0 \ddagger$ \\
Full scale & 62.00 & 89.88 & $14.0 \ddagger$ \\
& & & \\
\hline
\end{tabular}

* $\mathbf{P} \leqslant 0.05$ (two-tail)

$\dagger P \leqslant 0.02$ (two-tail).

$\ddagger P \leqslant 0.002$ (two-tail).

WAIS RESUlTS AT FOLLOW-UP The MannWhitney $U$ test was again employed to evaluate the significance of the differences between the group (Table 3). No statistically significant 
TABLE 3

WAIS MEAN (SCALE) SUBTEST AND IQ SCORES FOR TWO MATCHED GROUPS OF HEAD-INJURED SUBJECTS (FOLLOW-UP)

\begin{tabular}{lrrr}
\multicolumn{1}{c}{ Subtest } & $\begin{array}{c}\text { Group I } \\
(N=11)\end{array}$ & $\begin{array}{r}\text { Group II } \\
(N=11)\end{array}$ & $U$ \\
\hline Verbal subtests & & & \\
Information & 9.09 & 10.27 & $50.0 \mathrm{NS}$ \\
Comprehension & 11.09 & 12.09 & $50.5 \mathrm{NS}$ \\
Arithmetic & 8.36 & 11.00 & $34.0 \mathrm{NS}$ \\
Similaritics & 9.18 & 10.36 & $42.5 \mathrm{NS}$ \\
Digit span & 8.82 & 9.82 & $48.0 \mathrm{NS}$ \\
Vocabulary & 9.91 & 11.27 & $52.0 \mathrm{NS}$ \\
Performance subtests & & & \\
Digit symbol & 5.63 & 7.00 & $41.5 \mathrm{NS}$ \\
Picture completion & 8.82 & 9.45 & $51.0 \mathrm{NS}$ \\
Block design & 9.27 & 8.82 & $54.0 \mathrm{NS}$ \\
Picture arrangement & 7.27 & 8.18 & $50.0 \mathrm{NS}$ \\
Object assembly & 7.45 & 9.09 & $45.0 \mathrm{NS}$ \\
IQs & & & \\
Verbal & 97.45 & 105.91 & $46.0 \mathrm{NS}$ \\
Performance & 87.36 & 92.00 & $51.5 \mathrm{NS}$ \\
Full scale & 92.91 & 100.09 & $44.5 \mathrm{NS}$ \\
\hline
\end{tabular}

differences were found. However, on all subtests but one (Block Design) group I scored slightly lower than group II. This trend (binomial $P<0.001)$ suggested that, while at follow-up group I had substantially narrowed the 'cognitive gap' vis-à-vis group II, the longer PTA of the former group may have exerted a small but consistent effect.

CORRELATES OF WAIS AT INITIAL AND FOLLOW-UP ADMINISTRATIONS It is evident that there exists a quantitative difference in cognitive ability between the PTA condition and full consciousness. The question remains whether there is a qualitative difference also, such a difference being defined operationally as a change in the pattern of relationships between the WAIS scores and those clinical features of the head-injured patient which might be expected to contribute to his level of cognitive functioning.

Age and years of education, together with the clinical variables of Table 1 , were correlated with the WAIS (scale) subtest scores. The former two variables were treated as continuous, and product-moment correlation coefficients computed. The clinical variables were treated as dichotomous and scored $0=$ present, $1=$ absent ; for these variables point biserial $\left(r_{\text {pbis }}\right)$ correlations were computed (Guilford, 1956). By summating the clinical variables, a total 'clinical score' was obtained for each subject, which was also treated as a continuous variable. Table 4

TABLE 4

CORRELATIONS OF CLINICAL VARIABLES WITH WAIS SUBTESTS FOR TWO MATCHED GROUPS OF HEAD-INJURED SUBJECTS: INITIAL TESTING $\left(\mathrm{N}_{1}=\mathrm{N}_{2}=16\right)$

\begin{tabular}{|c|c|c|c|c|c|c|c|c|c|}
\hline WAIS subtest & Group & $A g c^{1}$ & Education $^{1}$ & Fracture $^{2}$ & Haematoma ${ }^{2}$ & $\begin{array}{c}\text { Motor } \\
\text { dysfunction }\end{array}$ & Dysphasia 2 & $\begin{array}{l}\text { Brain-stem } \\
\text { signs }^{2}\end{array}$ & $\begin{array}{l}\text { 'Clinical } \\
\text { score'1 }\end{array}$ \\
\hline \multirow[t]{2}{*}{ Information } & I & -39 & $-55^{*}$ & 33 & 31 & 42 & 49 & -21 & $53^{*}$ \\
\hline & II & -09 & 12 & 34 & 26 & 19 & -08 & -09 & 25 \\
\hline \multirow[t]{2}{*}{ Comprehension } & I & -36 & -03 & 06 & -02 & $54^{*}$ & 29 & 22 & 40 \\
\hline & II & -14 & 14 & $56^{*}$ & 33 & 07 & -21 & -16 & 25 \\
\hline \multirow[t]{2}{*}{ Arithmetic } & I & $-52^{*}$ & 49 & 36 & $59 *$ & 41 & 05 & -13 & $51^{*}$ \\
\hline & II & -09 & 10 & $52^{*}$ & 32 & 25 & -02 & -04 & 42 \\
\hline \multirow[t]{2}{*}{ Similarities } & I & -37 & 10 & 33 & 01 & 43 & 39 & 31 & $59^{*}$ \\
\hline & II & -37 & 32 & 48 & 47 & 02 & 13 & -14 & 40 \\
\hline \multirow[t]{2}{*}{ Digit span } & I & $-66 t$ & 21 & 37 & $54^{*}$ & 36 & 03 & 10 & $56^{*}$ \\
\hline & II & -18 & 17 & 48 & 34 & -03 & 05 & -17 & 28 \\
\hline \multirow[t]{2}{*}{ Vocabulary } & I & $-62 \dagger$ & $55^{*}$ & 47 & 31 & 25 & 03 & 21 & $52^{*}$ \\
\hline & II & 09 & 14 & 26 & 31 & 29 & 14 & 08 & 31 \\
\hline \multirow[t]{2}{*}{ Digit symbol } & I & -32 & 18 & -43 & 18 & $81 \dagger$ & 20 & 09 & 26 \\
\hline & II & -19 & 08 & 20 & 38 & 38 & 00 & -08 & 36 \\
\hline \multirow[t]{2}{*}{ Picture completion } & I & $-59^{*}$ & 33 & -09 & 41 & $57^{*}$ & 13 & -25 & 26 \\
\hline & II & -15 & 03 & 26 & -09 & 45 & 33 & 15 & 44 \\
\hline \multirow[t]{2}{*}{ Block design } & I & -34 & -31 & -16 & 06 & $60^{*}$ & -04 & 36 & 27 \\
\hline & II & -10 & -05 & 21 & -16 & 24 & $57 *$ & 08 & 39 \\
\hline \multirow[t]{2}{*}{ Picture arrangement } & I & -42 & -12 & -09 & 18 & $78+$ & 23 & 30 & 50 \\
\hline & II & -31 & 19 & $68+$ & 31 & -11 & 04 & 07 & 40 \\
\hline \multirow[t]{2}{*}{ Object assembly } & I & -37 & -14 & -22 & 27 & $62+$ & 00 & 13 & 26 \\
\hline & II & -31 & -15 & 32 & -12 & 29 & $54^{*}$ & 06 & 45 \\
\hline
\end{tabular}

1 Product moment coefficient (decimal point omitted).

2 Point-biserial coefficient (decimal point omitted).

$\dagger \mathrm{P} \leqslant 0.01 ; \quad * \mathrm{P} \leqslant 0.05$. 
TABLE 5

CORRELATIONS OF CLINICAL VARIABLES WITH WAIS SUBTESTS FOR TWO MATCHED GROUPS OF HEAD-INJURED SUBJECTS: FOLLOW-UP TESTING $\left(\mathrm{N}_{1}=\mathrm{N}_{2}=11\right)$

\begin{tabular}{|c|c|c|c|c|c|c|c|c|c|}
\hline WAIS subtest & Group & $A g e^{1}$ & Education ${ }^{1}$ & Fracture $^{2}$ & Haematoma $^{2}$ & $\begin{array}{c}\text { Motor } \\
\text { dysfunction } 2\end{array}$ & Dysphasia 2 & $\begin{array}{l}\text { Brain-stem } \\
\text { signs }^{2}\end{array}$ & $\begin{array}{l}\text { 'Clinical } \\
\text { score'1 }\end{array}$ \\
\hline \multirow[t]{2}{*}{ Information } & I & -58 & 27 & 39 & 32 & 34 & 60 & 10 & $77^{*}$ \\
\hline & II & -49 & 49 & 24 & 41 & 11 & -42 & -27 & 00 \\
\hline \multirow[t]{2}{*}{ Comprehension } & I & -53 & 41 & 38 & 39 & 31 & $63^{*}$ & -14 & $70^{*}$ \\
\hline & II & -37 & 21 & 44 & 38 & -09 & -23 & -21 & 15 \\
\hline \multirow[t]{2}{*}{ Arithmetic } & I & $-60^{*}$ & 40 & 45 & $65^{*}$ & 45 & $62 *$ & -14 & $89 \dagger$ \\
\hline & $\hat{I I}$ & -29 & -17 & $62^{*}$ & 29 & 38 & -15 & 00 & 37 \\
\hline Similarities & II & -59 & 52 & 19 & 46 & 09 & -02 & -41 & 08 \\
\hline \multirow[t]{2}{*}{ Digit span } & I & -39 & 13 & 30 & $68^{*}$ & 18 & 20 & -08 & 56 \\
\hline & II & -22 & 13 & 51 & 07 & 16 & -51 & -37 & -06 \\
\hline \multirow{2}{*}{ Vocabulary } & I & -52 & 42 & 37 & 16 & 31 & 54 & -08 & 57 \\
\hline & II & -30 & 50 & 10 & 28 & 15 & -40 & -22 & -06 \\
\hline \multirow[t]{2}{*}{ Digit symbol } & I & -47 & 53 & 43 & $60^{*}$ & 19 & -01 & 43 & 35 \\
\hline & II & -54 & 52 & 41 & 31 & 10 & -42 & -27 & 03 \\
\hline \multirow[t]{2}{*}{ Picture completion } & I & -57 & 33 & 13 & 39 & 49 & $64 *$ & -28 & 59 \\
\hline & II & -56 & 32 & 42 & 35 & 36 & 08 & -05 & 38 \\
\hline Block design & II & -53 & 03 & 40 & 37 & 43 & 04 & 03 & 42 \\
\hline \multirow{2}{*}{ Picture arrangement } & I & -59 & 40 & 24 & 49 & 56 & 51 & -27 & $65 *$ \\
\hline & II & -24 & -02 & 47 & 17 & 20 & -07 & 06 & 28 \\
\hline \multirow[t]{2}{*}{ Object assembly } & I & -10 & -03 & -15 & 06 & 52 & 31 & -01 & 28 \\
\hline & II & -42 & -10 & 43 & 27 & 57 & $\begin{array}{l}J 1 \\
29\end{array}$ & 30 & $63^{*}$ \\
\hline
\end{tabular}

1 Product moment coefficient (decimal point omitted).

2 Point biserial coefficient (decimal point omitted).

$+P \leqslant 0.01 ; * P \leqslant 0.05$.

presents the correlation matrices for the two groups at initial administration of the WAIS, while Table 5 presents the correlation matrices at follow-up. (The correlations with IQ scores were omitted on the ground that IQ represents no more than the age-weighted sum of the subtest scores.)

With the passage of time from initial to follow-up testing, there was a trend in both groups for the clinical variables to correlate non-significantly with WAIS scores. In the case of two clinical variables, motor dysfunction and education, significant correlations with the WAIS occurred only during PTA. The failure to find significant correlations involving these variables for group II at initial testing, and for both groups at follow-up, may be seen as evidence for a qualitatively distinct pattern of interaction between 'brain state' and cognitive level during PTA, though it is admitted that this evidence is less compelling for the correlations with education. In the case of the remaining clinical variables the picture remains confused (at no time, for example, did the presence of brain-stem injury correlate with WAIS level). For this reason an ad hoc attempt was made to consider each correlation matrix as a datum in its own right, and to test certain hypotheses concerning the effects of postulated qualitative differences between the PTA condition and full consciousness. This method is described in the Appendix.

\section{DISCUSSION}

DURATION OF PTA AND SEVERITY OF INJURY It may be objected that group I, by virtue of its longer mean PTA, might reasonably be regarded as having sustained more severe injuries than group II; hence, the former's lower WAIS scores at initial testing are to be interpreted as a function of more severe injury, rather than as a function of the PTA condition. In this respect, three points may be made. (1) The overlap between the two groups in respect of PTA duration (Table 1) reveals that, when severity is strictly interpreted as equivalent to PTA duration, approximately one-third of the subjects in each group had injuries of comparable severity. This situation in itself gives some force to the suggestion that the initial WAIS deficit was a function of being in PTA, rather than of greater severity of injury. (2) There is some doubt 
whether severity should in fact be so strictly interpreted. Conventional categories of severity defined in terms of PTA duration (Botterell and Wilson, 1945; Russell and Smith, 1961 ; Hooper, 1969), applied to the present groups, reveal that only two subjects in this study were 'severe' injuries (PTA one to seven days), while the remaining 30 subjects were all 'very severe' (PTA > one week). It would seem otiose to make finer distinctions within the 'very severe' injuries group without firm evidence that such distinctions were clinically meaningful, and previous investigators appear generally to have been content with established categories. (3) The follow-up study tends strongly to suggest on an empirical level the essential equivalence of the injuries in the two groups. Preliminary data presented by Bond (1974), to be analysed more fully in a later paper, suggest that PTA duration up to about three months affects only the rate, and not the eventual level, of WAIS recovery.

NATURE OF DEFICIT IN PTA The data of Table 2 -in particular, the IQs obtained by group I during PTA-require some further elucidation for their significance to be appreciated. The mean Verbal IQ of group I fell in the so-called 'borderline' range, whereas Performance IQ was clearly mentally deficient; nevertheless, it is important not to overestimate the Performance achievement of this group. The WAIS is scored in such a manner that a person who attempted each Performance subtest, but who succeeded in attaining only the minimum total scale score, would be assigned a Performance IQ of 35-69 depending on age. In the present instance, the inability of group I to sustain a substantial level of achievement on these subtests during PTA is testified to by the number who failed to reach even a minimum scale score of 1 on each of these tasks. These were: for Digit Symbol, 12/16; for Picture Completion 2/16; for Block Design, 7/16; for Picture Arrangement, 9/16; and for Object Assembly, 7/16. By contrast, only $1 / 16$ of group II obtained a scale score 0 on the Digit Symbol subtest at initial administration, while all obtained scores $\geqslant 1$ on the remaining Performance subtests. On turning to the Verbal subtests, however, the differences between the groups was much less marked. All 16 of group II obtained scale scores $\geqslant 1$ on all Verbal sub- tests; of group I, only $1 / 16$ scored 0 on Comprehension; $2 / 16$ on Similarities; and $3 / 16$ on Vocabulary.

Thus, while it remains possible for persons in PTA to make appropriate (and in some cases quite complex) verbal responses, the demands made by the Performance tasks appear to be such that even a relatively low level of achievement is difficult to maintain. Verbal abilities appear to be relatively intact during PTA, while non-verbal skills remain relatively in abeyance. Whether this is due to some particular non-verbal quality of the tasks themselves, whether to a possible dependence of these tasks upon the memory processes which are known to be disordered during PTA, or whether it is due, as Mandleberg and Brooks (1975) have argued, to the fact that the integration of a complex set of visual, spatial, and manual coordination skills renders the Performance tasks inherently more difficult than the Verbal ones, is an issue which permits of no resolution on the basis of the present data.

This research was supported by the National Fund for Research into Crippling Diseases, as part of a wider study of severe head injuries by Professor Bryan Jennett, Department of Neurosurgery, University of Glasgow. The author wishes to thank the consultants of the Division of Neurosurgery, Institute of Neurological Sciences, for their assistance and cooperation.

\section{REFERENCES}

Bond, M. R. (1974). Assessment of the psychological outcome of severe head injuries. Paper presented at CIBA Foundation Symposium on Outcome of Severe CNS Damage. London. (In press.)

Botterell, E. H., and Wilson, K. E. (1945). The active management (non-operative) of cranio-cerebral injuries. Reported before publication in Acute Injuries of the Head, p. 394. Edited by G. Rowbotham. Livingstone: Edinburgh.

Dunn, J., and Brooks, D. N. (1974). Memory and posttraumatic amnesia. IRCS (Research on Neurology and Neurosurgery; Psychiatry and Clinical Psychology; Psychology), 2, 1497.

Fodor, I. E. (1972). Impairment of memory functions after acute head injury. Journal of Neurology, Neurosurgery, and Psychiatry, 35, 819-924.

Guilford, J. P. (1956). Fundamental Statistics in Psychology and Education. McGraw-Hill: New York.

Hooper, R. (1969). Patterns of Acute Head Injury. Arnold: London.

Mandleberg, I. A., and Brooks, D. N. (1975). Cognitive recovery after severe head injury: 1 . Serial testing on Wechsler Adult Intelligence Scale. Journal of Neurology, Neurosurgery, and Psychiatry, 38, 1121-1126.

Ruesch, J., and Moore, B. E. (1943). Measurement of intellectual functions in the acute stage of head injury. Archives of Neurology and Psychiatry, 50, 165-170.

Russell, W. R. (1971). The Traumatic Amnesias. Oxford University Press: London. 
Russell, W. R., and Smith, A. (1961). Post-traumatic amnesia in closed head injury. Archives of Neurology, 5, 19-29.

Siegel, S. (1955). Non-Parametric Statistics. McGraw-Hill: New York.

Wechsler, D. (1955). Manual for the Wechsler Adult Intelligence Scale. Psychological Corporation: New York.

\section{APPENDIX}

If PTA represents a qualitatively distinct phase of recovery from head injury, it was hypothesized that this would be reflected in an unique pattern of intercorrelations between WAIS and clinical variables for Group I at the first administration-that is, during PTA. Group II at this time, being out of PTA, would have a different pattern of intercorrelations, which would tend to resemble the patterns found in both groups at follow-up. Owing to the small numbers and to the fact that the correlation matrices under consideration were neither square nor symmetrical, factor analysis could not be applied to resolve the question of similarity or difference in the structure of the matrices. Accordingly, the problem was attacked as follows:

(1) It was assumed that the importance of a clinical variable in contributing to level of function on the WAIS was in proportion to the number of subtests with which it correlated at a statistically significant level. Thus, it was possible to rank each clinical variable in respect of its contribution to the Verbal and Performance subtests separately. It was felt that, in a situation in which at least one or two significant correlations with the WAIS might be expected by chance for each clinical variable, this procedure had the advantage of making no a priori assumptions as to which clinical variables were irrelevant in contributing to WAIS level. (2) The similarity of the intercorrelation patterns could now be assessed as a function of changes in the rank order of the clinical variables contributing to WAIS level. It was hypothesized that (a) the rank orders for the two groups at first administration would be significantly different; (b) the rank order for group I at initial

TABLE 6

SPEARMAN RANK-ORDER CORRELATIONS (RHO) RELATIVE TO FOUR HYPOTHESES CONCERNING NATURE OF PTA ${ }^{1}$

\begin{tabular}{ccc}
\hline Hypothesis & Verbal tests & Performance tests \\
\hline (a) & $0.13(\mathrm{C})$ & $0.45(\mathrm{C})$ \\
(b) & $0.45(\mathrm{C})$ & $0.40(\mathrm{C})$ \\
(c) & $0.20(\mathrm{NC})$ & $0.71(\mathrm{C})^{*}$ \\
(d) & $1.00(\mathrm{C}) \dagger$ & $0.62(\mathrm{NC})$
\end{tabular}

1 See text for details of hypotheses. $+P \leqslant 0.01 ; * P \leqslant 0.05$. $\mathrm{C}=$ confirms that PTA is a qualitatively distinct phase of recovery. $\mathrm{NC}=$ does not confirm that PTA is a qualitatively distinct phase of recovery. testing would be significantly different from that at follow-up; (c) the rank orders of groups I and II at follow-up would be very similar; and (d) the rank order for group II at initial administration would resemble that at follow-up. These hypotheses were tested by computing Spearman rank-order correlation coefficients (rho) (Siegel, 1955), with results shown in Table 6. Differences would be reflected in low or even negative rhos; similarities by high rhos.

Of the four hypotheses, two were confirmed fully, both for the Verbal and the Performance subtests; the remaining two were partially confirmed. Of these, hypothesis (c), confirmed for the Performance subtests only, was perhaps the most critical for sustaining the view that the return of full consciousness heralds a qualitative change in the relationship between brain state and cognitive level. In the light of the preceding discussion we may ask, however, whether this distinction between verbal and non-verbal abilities is, after all, so surprising. Emergence from PTA appears to represent a move from a condition of being essentially unable to cope with the non-verbal tasks, to one of being able to do so, a change which may well in itself be regarded as qualitative. For the verbal tasks, on the other hand, the change is from a condition of being able to respond to a limited extent during PTA, to one of being able to respond to a greater extent during full consciousness: this change might well be seen as purely quantitative. Yet, if this were the case, it might be expected that the correlation pattern for the verbal subtests of group I at initial administration would resemble those of group II at both initial and follow-up testing, thus giving rise to high rhos in column 1 , rows 1 and 3 of Table 6. These were not found, and the evidence for a purely quantitative change in verbal abilities remains ambiguous.

It is tempting to speculate on the state of the brain during PTA which might account for these findings, but the present data provide few clues, and further speculation would suffer from being premature in view of our extremely sketchy knowledge of cognitive abilities during PTA. The only other study which, to this author's knowledge, may address this topic is that of Ruesch and Moore (1943), but the results of that investigation and of the present one are not directly comparable. Only one task (Digit Span) was common to both studies, while despite the use of pictorial material in the earlier paper, all the Ruesch and Moore tests had distinct overt verbal components. Moreover, although their patients were studied at a very early stage of recovery, those in semicoma, confused, or delirious states were not tested, and the possibility exists that it was precisely these who were in PTA, while the remainder were fully conscious. 